\title{
Vapour phase synthesis of salol over solid acids via transesterification
}

\author{
S Z MOHAMED SHAMSHUDDIN ${ }^{\mathrm{a}, *}$ and N NAGARAJU ${ }^{\mathrm{b}}$ \\ ${ }^{a}$ Solid State and Structural Chemistry Unit, Indian Institute of Science, Bangalore 560012 \\ ${ }^{\mathrm{b}}$ St. Joseph's Research Center, 46, Langford Road, Shanthinagar, Bangalore 560027 \\ e-mail: Em_Es@rediffmail.com
}

MS received 17 March 2009; revised 16 July 2009; accepted 7 September 2009

\begin{abstract}
The transesterification of methyl salicylate with phenol has been studied in vapour phase over solid acid catalysts such as $\mathrm{ZrO}_{2}, \mathrm{MoO}_{3}$ and $\mathrm{SO}_{4}^{2-}$ or $\mathrm{Mo}(\mathrm{VI})$ ions modified zirconia. The catalytic materials were prepared and characterized for their total surface acidity, BET surface area and powder XRD patterns. The effect of mole-ratio of the reactants, catalyst bed temperature, catalyst weight, flowrate of reactants, WHSV and time-on-stream on the conversion (\%) of phenol and selectivity (\%) of salol has been investigated. A good yield (up to $70 \%$ ) of salol with $90 \%$ selectivity was observed when the reactions were carried out at a catalyst bed temperature of $200^{\circ} \mathrm{C}$ and flow-rate of $10 \mathrm{~mL} / \mathrm{h}$ in presence of $\mathrm{Mo}(\mathrm{VI}) / \mathrm{ZrO}_{2}$ as catalyst. The results have been interpreted based on the variation of acidic properties and powder XRD phases of zirconia on incorporation of $\mathrm{SO}_{4}^{2-}$ or $\mathrm{Mo}(\mathrm{VI})$ ions. The effect of poisoning of acid sites of $\mathrm{SO}_{4}^{2-}$ or $\mathrm{Mo}(\mathrm{VI})$ ions modified zirconia on total surface acidity, powder XRD phases and catalytic activity was also studied. Possible reaction mechanisms for the formation of salol and diphenyl ether over acid sites are proposed.
\end{abstract}

Keywords. Salol; solid acids; diphenyl ether; zirconia; vapour phase transesterification.

\section{Introduction}

Solid acids are safe alternatives for conventional liquid acid catalysts used in synthetic organic chemistry in petroleum refineries, synthesis of fine chemicals, pharmaceuticals, etc. ${ }^{1}$ Due to the environmental hazards and technical difficulties associated with the use of liquid acids, extensive research is in progress to phase out these catalysts from chemical industry. Solid acids like zeolites, cation exchange resins, oxides and their modified forms and AlPOs have been used successfully as catalysts for several acid-catalysed reactions such as isomerisation, catalytic cracking, oligomerisation, dehydration, acylation, etc. ${ }^{2-6}$

Transesterification is an industrially important acid-catalysed reaction with wide range of applications. ${ }^{7-9}$ It is worthwhile to explore the possibility of finding a suitable environmentally benign solid catalyst for this reaction considering the fact that the existing procedures require expensive or corrosive acids and solvents which cannot be reused due to tedious methods of isolation. ${ }^{10}$

\footnotetext{
*For correspondence
}

Salicylate esters are an important group of esters used in perfumery, flavouring, sun tan preparations and sweeteners. ${ }^{11}$ Phenyl salicylate ester (Salol), which has got a pleasant taste and odour, is used in sun-tan lotions, as an antiseptic, anodyne and painrelieving agent. ${ }^{11}$ It is obtained by esterification of salicylic acid with phenol. ${ }^{12}$ As the solubility of salicylic acid in phenol is very low, this method requires the use of the latter in higher molar ratios. Hence, the method of transesterification of methyl salicylate with phenol is employed wherein the reactants, being mutually soluble in one another, can be mixed in different molar ratios. Also, the solid acid catalysts that have been chosen for this work are known to possess moisture-sensitive active centers, which get poisoned by water molecules produced during the direct esterification reaction between alcohol and the acid. ${ }^{13}$ Thus, the anhydrous condition prevalent in transesterification of methyl salicylate with isoamyl alcohol is an added advantage. Transesterification is an equilibrium-driven reaction. Hence, vapour-phase conditions of the experiment are better suited than liquid phase reaction conditions. In a vapour-phase reaction, the products of the reaction are not in contact with the catalysts during 
the entire reaction period, thereby preventing backward reaction.

$\mathrm{ZrO}_{2}$ is an interesting catalytic material and can be prepared in many ways in various modifications. It possesses acidic, basic, oxidizing and reducing properties on the surface and these four properties including phase modifications (monoclinic or tetragonal) change independently with the method of preparation and heat treatment. ${ }^{14,15}$ The acid-base properties of zirconia can be modified by the addition of anionic or cationic substances. Generally, it has been observed that the acidic properties of the modified forms of $\mathrm{ZrO}_{2}$ will be higher than $\mathrm{ZrO}_{2}$ itself. ${ }^{17}$ It has been reported that when zirconia is modified with $\mathrm{SO}_{4}^{2-}$ or $\mathrm{Mo}(\mathrm{VI})$ or $\mathrm{W}(\mathrm{VI})$ ions, their acidic properties increase drastically. ${ }^{16-18}$

The present paper contains the results of studies on vapour phase transesterification of methyl salicylate with phenol in the presence of solid acids such as $\mathrm{ZrO}_{2}, \mathrm{MoO}_{3}, \mathrm{SO}_{4}^{2-} / \mathrm{ZrO}_{2}$ and $\mathrm{Mo}(\mathrm{VI}) / \mathrm{ZrO}_{2}$ as catalysts. The catalytic activity of these materials has been studied in the synthesis of salol by transesterification method. The reaction conditions have been optimized by varying the reaction parameters such as, mole-ratio of the reactants, catalyst bed temperature, catalyst weight, flow-rate of reactants, WHSV and time-on-stream.

\section{Experimental}

\subsection{Preparation of catalysts}

(a) Hydrated zirconia was obtained by the precipitation method as follows. $25 \mathrm{~g}$ of $\mathrm{ZrOCl}_{2} \cdot 8 \mathrm{H}_{2} \mathrm{O}$ were dissolved in $250 \mathrm{~mL}$ deionised water. To this clear solution liquor ammonia (28\%) was added dropwise from a burette with constant stirring. Thus obtained precipitate of $\mathrm{Zr}(\mathrm{OH})_{4}$ was washed thoroughly to remove the soluble ions and dried in an air oven at $120^{\circ} \mathrm{C}$ for $12 \mathrm{~h}$.

(b) Molybdenum oxide $\left(\mathrm{MoO}_{3}\right)$ was prepared by mixing well $2 \mathrm{~g}$ of ammonium hepta molybdate $\left[\left(\mathrm{NH}_{4}\right)_{6} \quad \mathrm{Mo}_{7} \mathrm{O}_{24} \cdot 4 \mathrm{H}_{2} \mathrm{O}\right]$ with $2 \mathrm{~mL}$ distilled water followed by drying the resulting paste in an oven at $120^{\circ} \mathrm{C}$ for $12 \mathrm{~h}$.

(c) Sulfate ion and Mo(VI) modified zirconia were prepared as follows:

- Sulfated zirconia (SZ) was obtained by impregnating $3 \mathrm{~g}$ of hydrated zirconia with $1.5 \mathrm{~mL}$ of $3 \mathrm{M} \mathrm{H}_{2} \mathrm{SO}_{4}$. The mixture was thoroughly mixed to form a paste which was then dried in an air oven at $120^{\circ} \mathrm{C}$ for $12 \mathrm{~h}$.

- $\mathrm{Mo}(\mathrm{VI}) / \mathrm{ZrO}_{2}$ (MZ) containing $2 \%$ of $\mathrm{Mo}(\mathrm{VI})$ was prepared by wet impregnating $3 \mathrm{~g}$ of hydrated zirconia with $0.2 \mathrm{~g}$ of $\left(\mathrm{NH}_{4}\right)_{6} \mathrm{Mo}_{7} \mathrm{O}_{24} \cdot 4 \mathrm{H}_{2} \mathrm{O}$. The resulting wet mixture of the $\mathrm{Mo}(\mathrm{VI})$ salt and hydrated zirconia was dried at $120^{\circ} \mathrm{C}$ for $12 \mathrm{~h}^{20}$

The hydrated zirconia and its $\mathrm{SO}_{4}^{2-}$ and $\mathrm{Mo}(\mathrm{VI})$ ions modified forms were calcined to $550^{\circ} \mathrm{C}$ for $5 \mathrm{~h}$ in a muffle furnace before their use as catalysts.

\subsection{Catalyst characterization}

All the catalysts were analyzed for their total surface acidity, BET surface area, and powder XRD. The total surface acidity was measured by $\mathrm{NH}_{3}$-TPD method by using AutoChem-2910 instrument and also by $n$-butyl amine back titration method using dry benzene as the solvent and bromothymol blue indicator. ${ }^{21}$ The BET surface area of the samples was determined using nitrogen as the adsorbent in a NOVA-1000 high speed gas sorption analyzer version-3.70. The X-ray powder diffraction patterns of all the samples were collected on Seimens-D5005 $\mathrm{X}$-ray diffractometer with a $\mathrm{Ni}$ filtered $\mathrm{Cu}-\mathrm{K} \alpha$ radiation $(1.5418 \AA)$.

\subsection{Catalytic activity}

Catalytic activity of the catalyst samples was determined in vapour phase transesterification of methyl salicylate with phenol. The reactions were carried out in a fixed bed continuous down flow glass tube reactor (i.d. $30 \mathrm{~mm}$ ) heated by tubular furnace with a temperature control. In a typical reaction, $1.0 \mathrm{~g}$ of the catalyst (mesh $18-30$ ) pre-calcined at $550^{\circ} \mathrm{C}$ was placed over glass wool in the reactor maintained at $200^{\circ} \mathrm{C}$. The reaction mixture containing methyl salicylate and phenol in 1:1 molar ratio was introduced into the pre-heater maintained at $250^{\circ} \mathrm{C}$ by means of an infusion pump before passing over the catalyst. The reaction mixture was fed into the reactor using a flow-rate controller. The liquid products were collected at the bottom of the reactor at time intervals of $15 \mathrm{~min}$. Each reaction was carried out for $1 \mathrm{~h}$. Further studies on the effect of mole-ratio of the reactants, catalyst bed temperature, catalyst weight, flow-rate of the reactants, WHSV and time-onstream on the conversion (\%) of phenol and selectivity towards salol was studied. 
Table 1. Physico-chemical properties of solid acids used.

\begin{tabular}{lccccc}
\hline & \multicolumn{5}{c}{ Acidity distribution obtained by $\mathrm{NH}_{3}-\mathrm{TPD}(\mathrm{mmol} / \mathrm{g})$} \\
\cline { 2 - 6 } Catalyst & $\begin{array}{c}\text { BET surface } \\
\text { area }\left(\mathrm{m}^{2} / \mathrm{g}\right)\end{array}$ & $\begin{array}{c}\text { Medium } \\
\left(150-250^{\circ} \mathrm{C}\right)\end{array}$ & $\begin{array}{c}\text { Strong } \\
\left(250-410^{\circ} \mathrm{C}\right)\end{array}$ & $\begin{array}{c}\text { Very strong } \\
\left(>410^{\circ} \mathrm{C}\right)\end{array}$ & Total \\
\hline $\mathrm{ZrO}_{2}$ & 71 & 0.40 & - & - & $0 \cdot 40(0 \cdot 44)$ \\
$\mathrm{MoO}_{3}$ & 79 & 0.46 & 0.05 & - & $0 \cdot 51(0 \cdot 53)$ \\
$\mathrm{SZ}$ & 149 & - & 0.89 & $0 \cdot 26$ & $1 \cdot 15(1 \cdot 09)$ \\
$\mathrm{MZ}$ & 116 & 0.09 & 0.91 & - & $1.00(1 \cdot 01)$ \\
$\mathrm{SZ}$ (poisoned) & 146 & - & 0.26 & 0.09 & $0 \cdot 35(0 \cdot 36)$ \\
$\mathrm{MZ}$ (poisoned) & 113 & 0.03 & 0.29 & - & $0.32(0 \cdot 30)$ \\
\hline
\end{tabular}

Numbers in the parenthesis correspond to the total surface acidity values obtained by $n$-butyl amine back titration method

The products obtained after the reactions were analysed quantitatively by gas chromatograph fitted with a (10\% SE-30 chromosorb w-AW, $\left.3 \mathrm{~m} \times 1 / 8^{\prime \prime}\right)$ column coupled with FID detector and qualitatively by GC-MS (Varian).

\section{Results and discussion}

\subsection{Catalyst characterization}

The values of BET surface area and total surface acidity along with acid site distribution of all the catalysts used in this investigation are presented in table 1 .

The total acidity of the catalysts measured both by $\mathrm{NH}_{3}$-TPD and $n$-butylamine titration method was found to follow the order:

$$
\mathrm{ZrO}_{2}<\mathrm{MoO}_{3}<\mathrm{MZ} \leq \mathrm{SZ} .
$$

$\mathrm{ZrO}_{2}$ being an amphoteric oxide showed least acidity where as $\mathrm{SO}_{4}^{2-} / \mathrm{ZrO}_{2}$ (SZ) and $\mathrm{Mo}(\mathrm{VI}) / \mathrm{ZrO}_{2}(\mathrm{MZ})$ showed higher surface acidity when compared with pure zirconia. When $\mathrm{SO}_{4}^{2-}$ ions are doped on hydrated $\mathrm{ZrO}_{2}$ the basic sites are expected to be suppressed. This effect indirectly increases the number of acidic sites which are known to be responsible for their enhanced catalytic activity. ${ }^{15} \mathrm{Mo}(\mathrm{VI}) / \mathrm{ZrO}_{2}$ catalyst was found to have higher surface acidity than pure zirconia due to electron deficient states formed by the introduction of Mo(VI) ions in the lattice of zirconia solid. ${ }^{22}$ Chary et $a l^{23}$ has reported that increase in the acidity of MZ is due to molybdena phase. Further, it is well-established that in $\mathrm{NH}_{3}$-TPD measurement, based on the temperature at which $\mathrm{NH}_{3}$ molecules desorb from the surface of a solid acid catalyst, the strength of acid sites can be classified as 'medium', 'strong' and 'very strong'. It has also been reported that pure $\mathrm{ZrO}_{2}$ contains 'medium' acidic sites, $\mathrm{SO}_{4}^{2-} / \mathrm{ZrO}_{2}$ contains 'strong' and 'very strong' acidic sites and $\mathrm{Mo}(\mathrm{VI}) / \mathrm{ZrO}_{2}$ contains 'medium' and 'strong' acidic sites. ${ }^{23,24}$

The specific surface area of $\mathrm{SO}_{4}^{2-} / \mathrm{ZrO}_{2}$ and $\mathrm{Mo}(\mathrm{VI}) / \mathrm{ZrO}_{2}$ was significantly higher than that of pure $\mathrm{ZrO}_{2}$. According to Arata ${ }^{16}$, higher surface area of $\mathrm{SO}_{4}^{2-} / \mathrm{ZrO}_{2}$ was found to be due to the cracking of $\mathrm{ZrO}_{2}$ crystallites into fine particles upon treatment with sulfate ions. Whereas in the case of $\mathrm{Mo}(\mathrm{VI}) /$ $\mathrm{ZrO}_{2}$ sample the observed increase in the specific surface area was explained based on the formation of Mo-O-Zr linkages resulting a porous material. ${ }^{25}$

Typical powder X-ray diffractograms of pure $\mathrm{ZrO}_{2}$, sulfate and $\mathrm{Mo}(\mathrm{VI})$ modified zirconia are presented in figure 1. The powder XRD patterns of pure $\mathrm{ZrO}_{2}$ showed the presence of both monoclinic $(2 \theta=24 \cdot 7$, $28.4,31.6)$ and tetragonal phases $(2 \theta=30 \cdot 3,35 \cdot 3$, $50 \cdot 7$ ). When the powder XRD patterns of pure $\mathrm{ZrO}_{2}$ and its sulfate and $\mathrm{Mo}(\mathrm{VI})$ ions modified forms were compared, the modified forms consists of more of tetragonal phase than monoclinic. This was attributed to the strong interaction of sulfate and Mo(VI) ions with zirconia support inhibiting the growth of monoclinic phase of zirconia. ${ }^{22}$ No peaks corresponding to either $\mathrm{MoO}_{3}$ or $\mathrm{ZrMo}_{2} \mathrm{O}_{8}$ in $\mathrm{Mo}(\mathrm{VI}) / \mathrm{ZrO}_{2}$ sample were observed.

It is interesting to note that there is a good correlation between the increases in surface acidity of $\mathrm{ZrO}_{2}$ on incorporation with sulfate or $\mathrm{Mo}(\mathrm{VI})$ ions and a decrease in the monoclinic phase with the similar modification with a corresponding increase in the tetragonal phase (figure 1). These observations indicate that the tetragonal phase of zirconia is associated with acid sites that are catalytically active in bringing about the transesterification of methyl 
salicylate and phenol. In order to confirm the relation between surface acidity, powder XRD phases and catalytic activity of $\mathrm{ZrO}_{2}$ and its modified forms, the following studies on poisoning of acid sites on $\mathrm{SZ}$ and $\mathrm{MZ}$ were taken up.

At the first instance, when total surface acidity and powder XRD phases of calcined pure $\mathrm{ZrO}_{2}$ are compared with that of calcined SZ and $\mathrm{MZ}$, the surface acidity values of latter are higher than pure $\mathrm{ZrO}_{2}$ and the powder XRD phases of $\mathrm{SZ}$ and $\mathrm{MZ}$ have more of tetragonal phase than monoclinic phase. In order to evaluate this, the acidic sites on calcined $\mathrm{SZ}$ and $\mathrm{MZ}$ were poisoned by exposing them to $\mathrm{NH}_{3}$ vapours for $\sim 15 \mathrm{~min}$ and heating it to $120^{\circ} \mathrm{C}$ for $2 \mathrm{~h}$ in an air oven. By this time all the acid sites on the surface of the catalyst get neutralized by $\mathrm{NH}_{3}$.

The total surface acidity of these poisoned SZ and MZ samples were measured and their powder XRD patterns were recorded. It was observed that the total surface acidity of the poisoned SZ and MZ was decreased to an extent that it was slightly less than the total surface acidity of pure $\mathrm{ZrO}_{2}$. This suggests that the acidic sites arising due to only $\mathrm{ZrO}_{2}$ were also

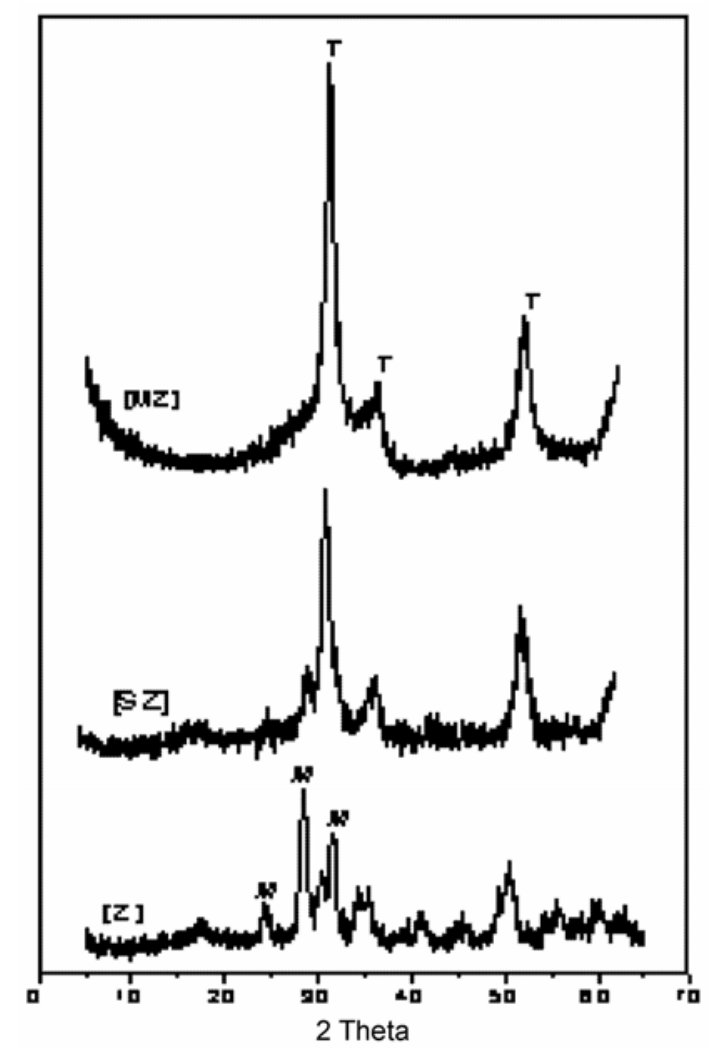

Figure 1. Powder XRD patterns of $\mathrm{ZrO}_{2}(\mathrm{Z}), \mathrm{SO}_{4}^{2-} / \mathrm{ZrO}_{2}$ (SZ) and $\mathrm{Mo}(\mathrm{VI}) / \mathrm{ZrO}_{2}(\mathrm{MZ})$ samples calcined at $823 \mathrm{~K}$ : $M$-monoclinic $\mathrm{ZrO}_{2}$ and $T$-tetragonal $\mathrm{ZrO}_{2}$. neutralized by $\mathrm{NH}_{3}$ to a certain extent in addition to the acidic sites formed due to modification of $\mathrm{ZrO}_{2}$ with $\mathrm{SO}_{4}^{2-}$ or $\mathrm{Mo}(\mathrm{VI})$ ions. It is interesting to note that the powder XRD of poisoned SZ and MZ resembled to those of pure $\mathrm{ZrO}_{2}$ i.e. former samples had got more of monoclinic phase than tetragonal phase (figure 2). When the intensities of powder XRD lines corresponding to monoclinic phases of poisoned $\mathrm{SZ}$ and $\mathrm{MZ}$ were compared with that of pure $\mathrm{ZrO}_{2}$, poisoned $\mathrm{SZ}$ and $\mathrm{MZ}$ had more intense powder XRD lines corresponding to monoclinic phase than tetragonal. But, however not much change in the BET surface area of poisoned SZ and MZ and the unpoisoned ones were observed which indicates that poisoning of acid sites does not affect surface area. Poisoning only neutralizes the acid sites without affecting the surface area of catalytic materials.

\subsection{Catalytic activity}

In general, it was found that all the catalysts used for the study exhibited good catalytic activity in trans-

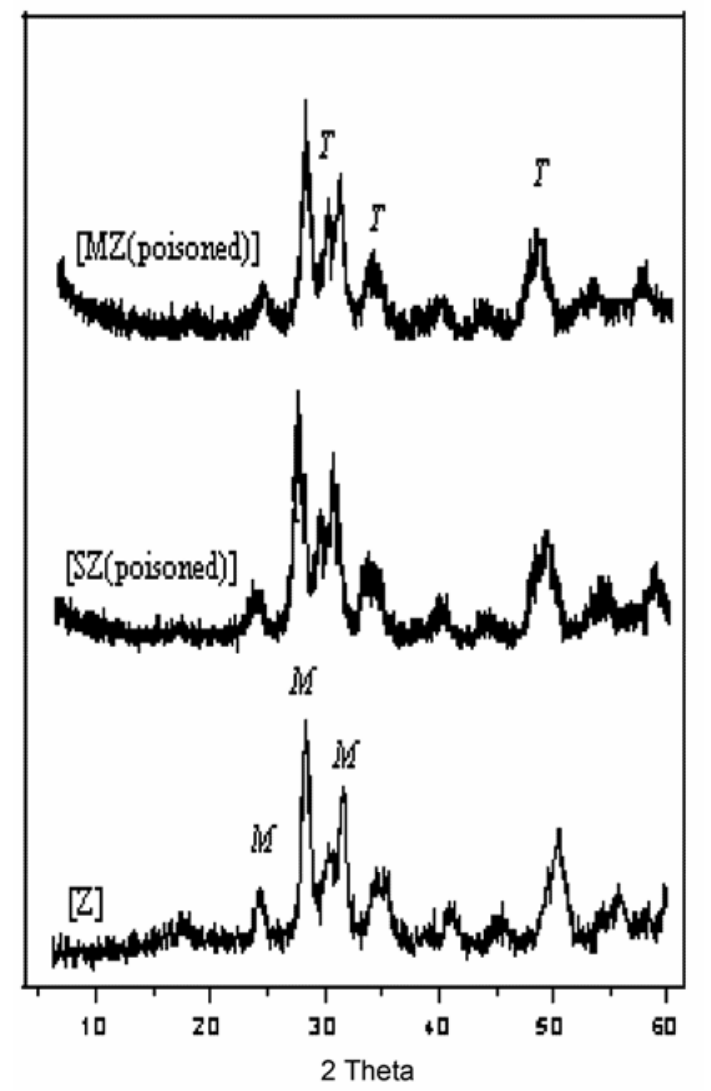

Figure 2. Powder X-ray diffraction patterns of $\mathrm{ZrO}_{2}$ (Z), poisoned- $\mathrm{SO}_{4}^{2-} / \mathrm{ZrO}_{2}$ (SZ poisoned) and poisoned$\mathrm{Mo}(\mathrm{VI}) / \mathrm{ZrO}_{2}$ (MZ poisoned) samples: $M$, monoclinic $\mathrm{ZrO}_{2}$ and $T$, tetragonal $\mathrm{ZrO}_{2}$. 
Table 2. Comparative catalytic activity of various catalysts in vapour phase transesterification (molar ratio of methyl salicylate: phenol $=1: 1$; amount of catalyst $=1.0 \mathrm{~g}$; flow-rate of reactants $=10 \mathrm{~mL} / \mathrm{h}$; catalyst bed temperature $=200^{\circ} \mathrm{C}$ ).

\begin{tabular}{lcccc}
\hline Catalysts & $\begin{array}{c}\text { Yield of } \\
\text { salol }\end{array}$ & $\begin{array}{c}\text { Conversion } \\
\text { of phenol (\%) }\end{array}$ & $\begin{array}{c}\text { Selectivity } \\
\text { towards salol (\%) }\end{array}$ & $\begin{array}{c}\text { Selectivity towards } \\
\text { diphenyl ether (\%) }\end{array}$ \\
\hline $\mathrm{ZrO}_{2}$ & $39 \cdot 06$ & 42 & 93 & 6 \\
$\mathrm{MoO}_{3}$ & $41 \cdot 86$ & 46 & 91 & 8 \\
$\mathrm{SZ}$ & $59 \cdot 04$ & 72 & 82 & 18 \\
$\mathrm{MZ}$ & 63.00 & 70 & 90 & 10 \\
$\mathrm{SZ}$ (poisoned) & $36 \cdot 66$ & 39 & 94 & 5 \\
$\mathrm{MZ}$ (poisoned) & 37.60 & 40 & 94 & 4 \\
\hline
\end{tabular}

esterification of methyl salicylate with phenol. However, there was no activity towards transesterification when the reaction was conducted in the absence of any catalyst indicating that the above said reaction is a catalysed reaction.

The results pertaining to the catalytic activity of the catalysts $\mathrm{ZrO}_{2}, \mathrm{MoO}_{3}, \mathrm{SZ}$ and $\mathrm{MZ}$ investigated in vapour phase transesterification of methyl salicylate with phenol for the synthesis of salol are presented in table 2. It was observed that apart from the desired product salol and primary by-product methanol, diphenyl ether was also formed as the sideproduct over all the catalysts. The high reaction temperatures may facilitate the dehydration of phenol and hence favour the ether formation. But over SZ catalyst the formation of diphenyl ether was more which may be attributed to the presence of very strong acidic sites which facilitate the dehydration of phenol and formation of diphenyl ether that is found to be absent in $\mathrm{ZrO}_{2}, \mathrm{MoO}_{3}$ and MZ. Optimization of reaction conditions was carried out in presence of $\mathrm{Mo}(\mathrm{VI}) / \mathrm{ZrO}_{2}$ catalyst because it showed good conversion (\%) of phenol with reasonably good selectivity towards salol.

3.2a Effect of mole-ratio of the reactants: The mole-ratio of the feed mixture (methyl salicylate: phenol) was varied from $2: 1$ to $1: 2$. It was observed that an increase in the concentration of methyl salicylate (MS) increases the conversion of phenol (figure 3). Since, transesterification is a reversible reaction; excess of MS favours the forward reaction, leading to formation of the desired product. However, increase in the concentration of phenol decreased the formation of salol with a slight increase in the formation of diphenyl ether. This may be because excess of phenol favours the formation of diphenyl ether. Further, it was also observed that in the presence of excess of phenol catalyst was getting deactivated.

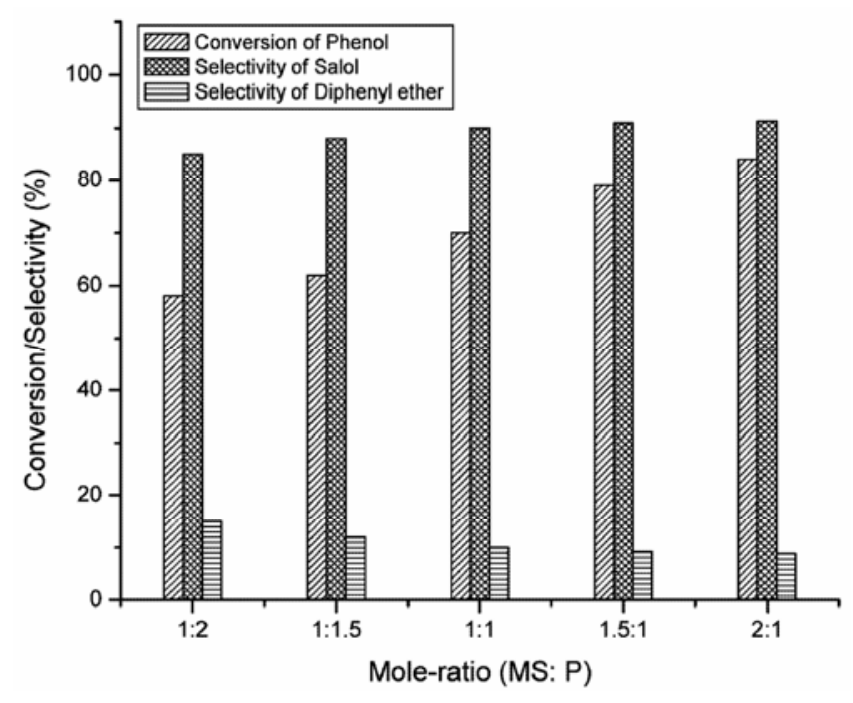

Figure 3. Effect of mole-ratio of the reactants on the phenol conversion (\%) and selectivity of the products (\%). (Amount of the catalyst $(\mathrm{MZ})=1.0 \mathrm{~g}$; flow-rate of the reactants $=10 \mathrm{~mL} / \mathrm{h}$; catalyst bed temperature $=$ $200^{\circ} \mathrm{C}$; pre-heater temperature $=250^{\circ} \mathrm{C}$.)

3.2b Effect of catalyst bed temperature: Suitable temperature conditions for transesterification reaction was determined by varying catalyst bed temperature between $150^{\circ} \mathrm{C}$ and $300^{\circ} \mathrm{C}$ keeping the preheater temperature fixed at $250^{\circ} \mathrm{C}$. As can be seen in figure 4 , at temperatures less than $200^{\circ} \mathrm{C}$, the formation of diphenyl ether was less. Further, at this temperature, the conversion of phenol was also low. When the catalyst bed temperature was higher than $200^{\circ} \mathrm{C}$, the temperature was found to be too high because the selectivity towards salol was decreased (from 10 to $14 \%$ ) and the side-product (diphenyl ether) formation was high. Traces of other impurities were also formed at higher catalyst bed temperature and by noticing the colour of the catalyst we can say that the catalyst was getting deactivated might be due to the polymerization of reactants or the products. 
Therefore, a catalyst bed temperature of $200^{\circ} \mathrm{C}$ was found to be suitable for reasonable conversion of phenol with good selectivity towards salol.

3.2c Effect of catalyst weight: The catalysts calcined to $550^{\circ} \mathrm{C}$ were used in the transesterification reaction in amounts ranging from $0.1 \mathrm{~g}$ to $2.0 \mathrm{~g}$ and

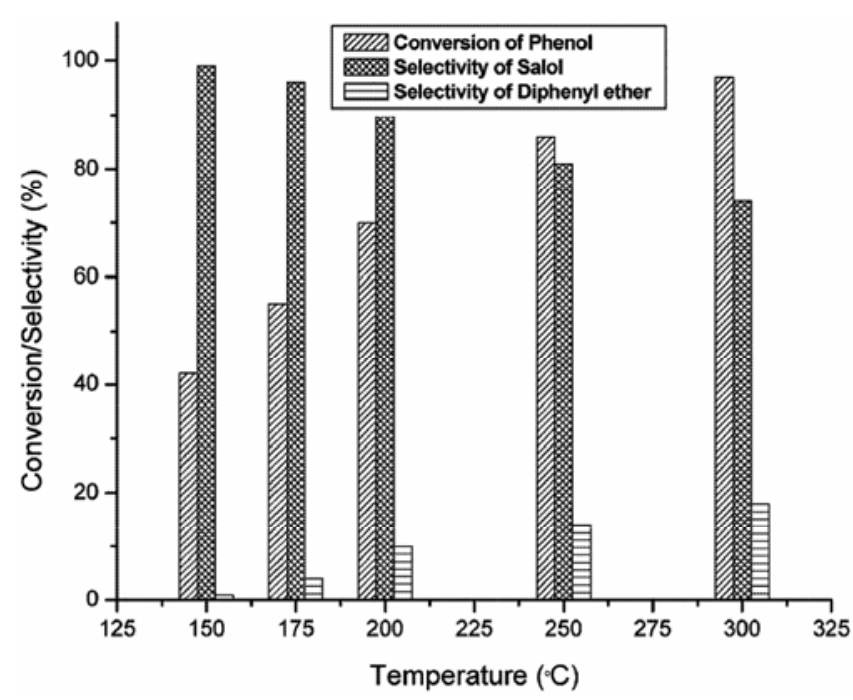

Figure 4. Effect of catalyst bed temperature on the phenol conversion (\%) and selectivity of the products $(\%)$. (Molar ratio of the reactants $=1: 1$; amount of the catalyst $(\mathrm{MZ})=1.0 \mathrm{~g}$; flow-rate of the reactants $=$ $10 \mathrm{~mL} / \mathrm{h}$; pre-heater temperature $=250^{\circ} \mathrm{C}$.)

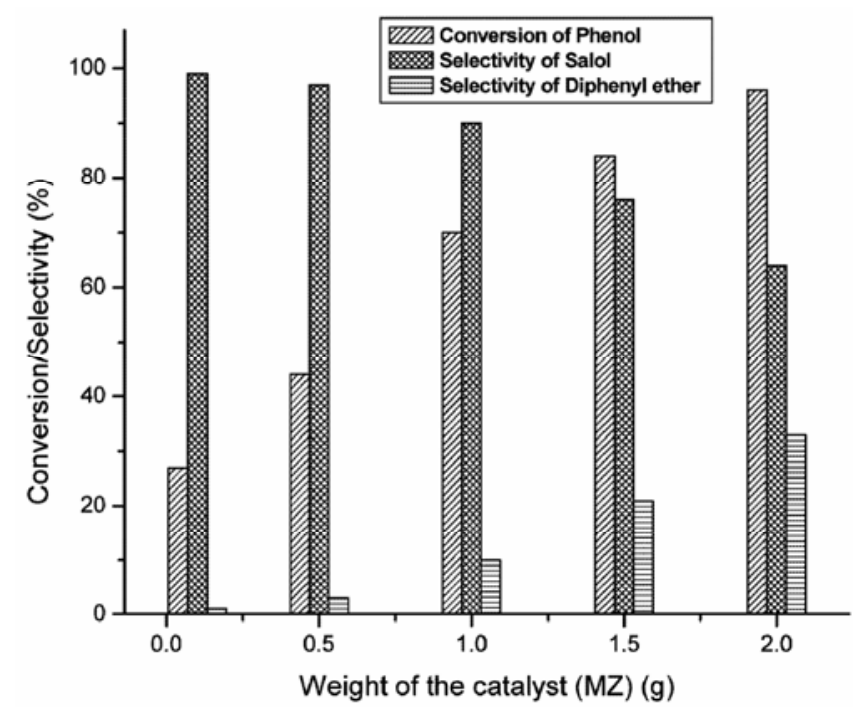

Figure 5. Effect of catalyst weight on the phenol conversion (\%) and selectivity of the products (\%). (Molar ratio of the reactants $=1: 1$; catalyst bed temperature $=$ $200^{\circ} \mathrm{C}$; flow-rate of the reactants $=10 \mathrm{~mL} / \mathrm{h}$; pre-heater temperature $=250^{\circ} \mathrm{C}$.) the results are presented in figure 5 . When the amount of catalyst was less than $1.0 \mathrm{~g}$, conversion of phenol was less. As the amount of catalyst was increased beyond $1.0 \mathrm{~g}$, the conversion of phenol increased and the selectivity towards salol decreased with an increase in the formation of diphenyl ether. This may be because, as the thickness of the catalyst-bed increases, the product molecules may get trapped within the catalyst layer leading to side-product formation. Decrease in the selectivity of salol at higher catalyst weights may also be to a certain extent due to back-pressure generated due to fine powder form of the catalyst.

\section{2d Effect of flow-rate (feed-rate) of reactants:}

The transesterification reaction was studied at different flow-rates between $2.5 \mathrm{~mL} / \mathrm{h}$ to $12.5 \mathrm{~mL} / \mathrm{h}$. From figure 6 , it is clear that the conversion of phenol decreases with increasing flow-rate of the reactants. However, at higher flow-rates selectivity of salol was found to increase with a decrease in the selectivity of diphenyl ether. This may be attributed to the higher contact time of reactant and product molecules on the catalyst when the flow-rate is less. A higher contact time could probably result in further reaction of reaction intermediates or products leading to the formation of side-products.

3.2e Effect of WHSV: Weight hourly space velocity (WHSV) was varied from 11 to $43 \mathrm{~g}$-cat.h. $\mathrm{mol}^{-1}$ by

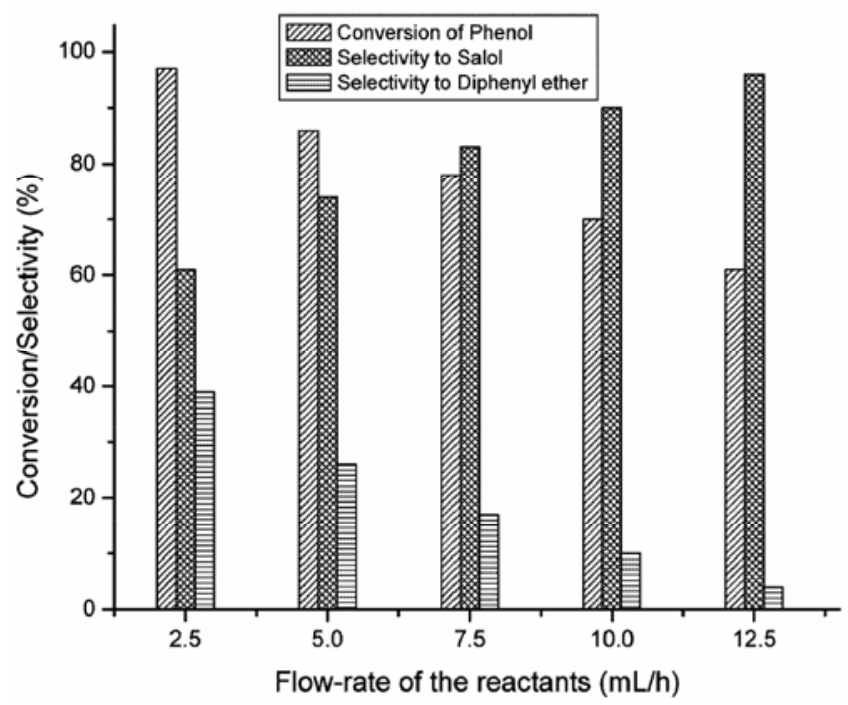

Figure 6. Effect of flow-rate on the phenol conversion (\%) and selectivity of the products (\%). (Molar ratio of the reactants $=1: 1$; amount of the catalyst $(\mathrm{MZ})=1.0 \mathrm{~g}$; catalyst bed temperature $=200^{\circ} \mathrm{C}$; pre-heater temperature $=250^{\circ} \mathrm{C}$.) 
keeping mole-ratio and reaction temperature constant (figure 7). With increasing WHSV there is an increase in the conversion, which is due to the increased residence time (contact time) of the reactants with the catalyst. However, selectivity towards salol decreased with increase in WHSV. This may be due to the higher contact time which leads to fur-

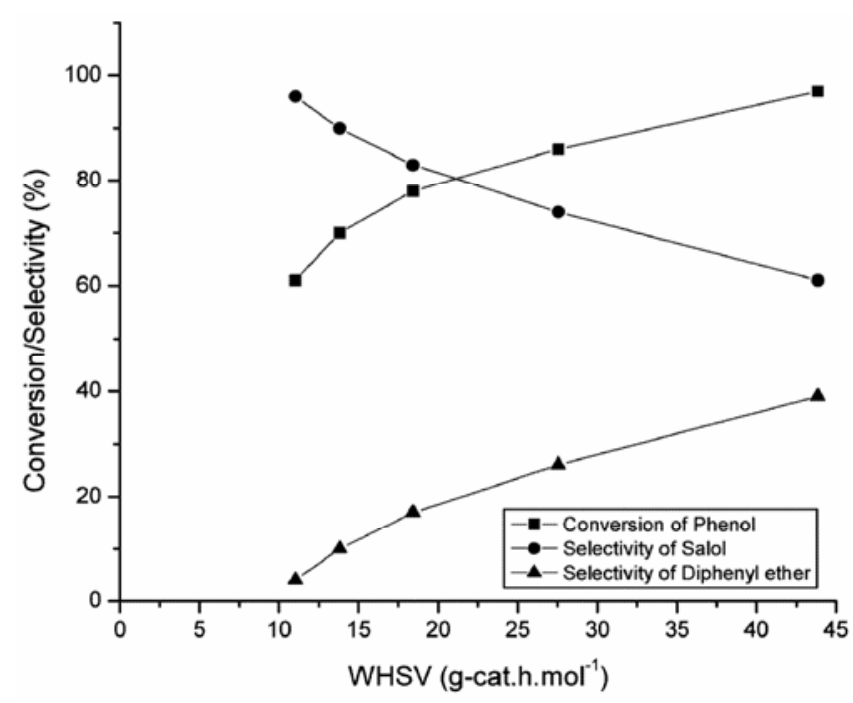

Figure 7. Effect of WHSV on the phenol conversion (\%) and selectivity of the products (\%). (Molar ratio of the reactants $=1: 1$; amount of the catalyst $(\mathrm{MZ})=1.0 \mathrm{~g}$; catalyst bed temperature $=200^{\circ} \mathrm{C}$; pre-heater temperature $=250^{\circ} \mathrm{C}$.)

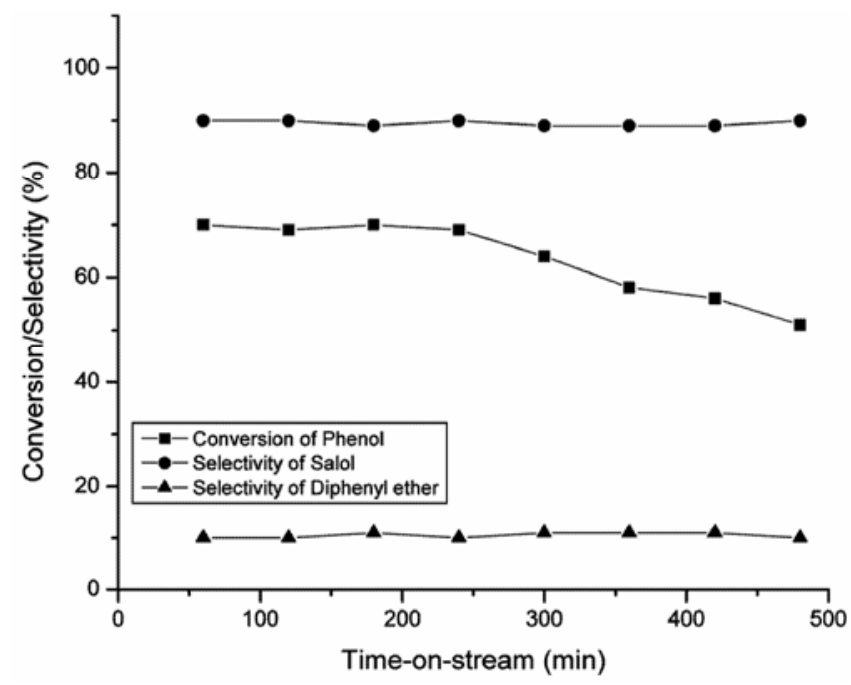

Figure 8. Effect of time-on-stream on the phenol conversion (\%) and selectivity of the products (\%). (Molar ratio of the reactants $=1: 1$; amount of the catalyst $(M Z)=1.0 \mathrm{~g}$; flow-rate of the reactants $=10 \mathrm{~mL} / \mathrm{h}$; catalyst bed temperature $=200^{\circ} \mathrm{C}$; pre-heater temperature $=250^{\circ} \mathrm{C}$.) ther reaction of reactants or reaction intermediates or products to produce more side-products.

3.2f Effect of time-on-stream: The time-on-stream experiments were carried over MZ catalyst at a catalyst bed temperature of $200^{\circ} \mathrm{C}$ and the results are represented in the form of a graph (figure 8). The conversion of phenol stays fairly steady up to $4 \mathrm{~h}$ but then decreases gradually up to $8 \mathrm{~h}$. The selectivity of salol or diphenyl ether remained rather steady throughout the time-on-stream experiment.

\section{$3.2 \mathrm{~g}$ Effect of poisoning of acid sites of $S Z$ and $M Z$} catalysts on catalytic activity: As discussed in the section 'catalyst characterization' under 'results and discussion' the acid sites of SZ and MZ catalysts were poisoned by $\mathrm{NH}_{3}$ vapours. It was observed that total surface acidity and powder XRD phases of zirconia and its modified forms are related to each other. In order to support this further, the poisoned catalysts were used in the title reaction and the results are included in table 2 . The decrease in the values of conversion (\%) of phenol can be attributed to the loss of acidic sites of SZ and MZ on poisoning. Hence, we can infer that the total surface acidity, powder XRD phases and the catalytic activity of zirconia and modified zirconia are linked with each other.

\subsection{Mechanism for salol formation over an acid site}

Transesterification takes palace between methyl salicylate adsorbed on the acid site of catalyst forming an electrophile, and phenol in the vapour phase (scheme 1) forming salol with subsequent removal of a molecule of methanol.

\subsection{Mechanism for ether formation over an acid site}

Formation of diphenyl ether from phenol via dehydration involves interaction between an acid site on the catalyst surface and a molecule of phenol followed by nucleophilic attack from a second phenol molecule and subsequent removal of a water molecule (scheme 2).

\section{Conclusions}

Phenyl salicylate (salol) can be conveniently synthesized by vapour phase transesterification of methyl 


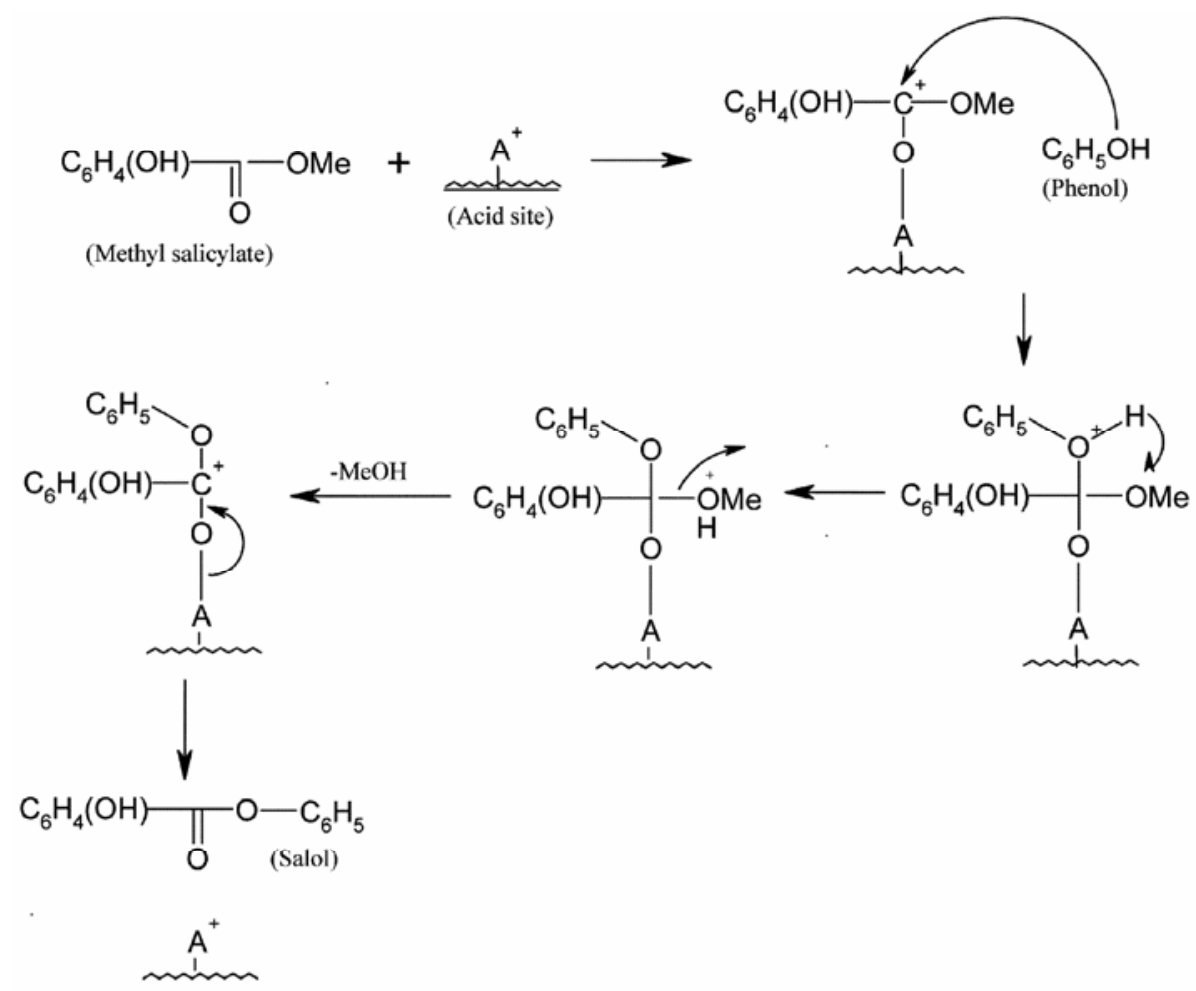

Scheme 1. Mechanism for salol formation over an acid site.
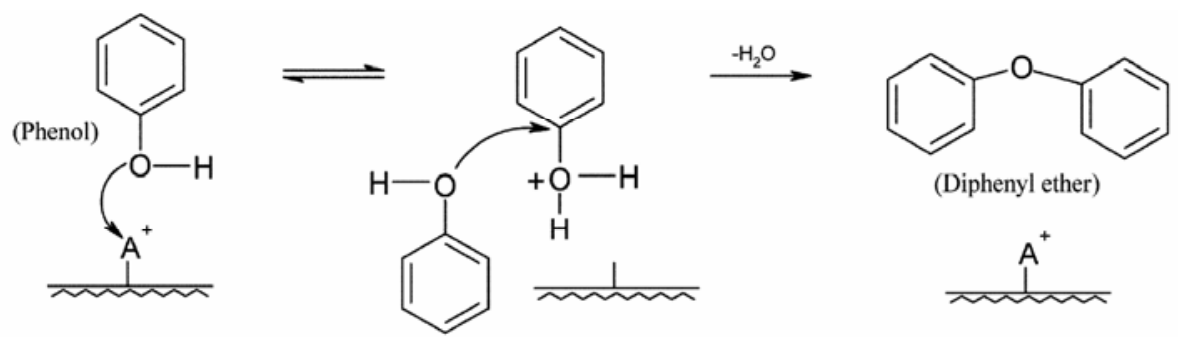

Scheme 2. Mechanism for ether formation over an acid site.

salicylate with phenol using $\mathrm{ZrO}_{2}, \mathrm{MoO}_{3}, \mathrm{SO}_{4}^{2-} / \mathrm{ZrO}_{2}$ and $\mathrm{Mo}(\mathrm{VI}) / \mathrm{ZrO}_{2}$ as catalysts. Among all the catalysts, $\mathrm{Mo}(\mathrm{VI}) / \mathrm{ZrO}_{2}$ showed good conversion (\%) of phenol with reasonably good selectivity towards salol. Although, $\mathrm{ZrO}_{2}$ and $\mathrm{MoO}_{3}$ showed good selectivity towards salol but their conversion (\%) of phenol is poor. Over $\mathrm{SO}_{4}^{2-} / \mathrm{ZrO}_{2}$ catalyst even though the conversion (\%) of phenol is high the selectivity towards salol decreased due to the formation of more diphenyl ether. Catalyst bed temperature of $200^{\circ} \mathrm{C}$ with flow-rate of reactant mixture at $10 \mathrm{~mL} / \mathrm{h}$ with $1.0 \mathrm{~g}$ of catalyst was found to be the optimal reaction condition to get good yield of salol with high selectivity. A linear correlation between the total surface acidity, powder XRD phases and the catalytic activity of the catalysts was observed.

\section{Acknowledgements}

The authors gratefully acknowledge the help extended by the authorities of Indian Institute of Science (IISc), Bangalore for permitting the use of library facilities, Prof. M S Hegde for his useful discussions, Dr. C Shivakumar, Indian Institute of Science (IISc) for powder XRD analysis, Dr Jaiprakash Bangalore Institute of Technology (BIT), Bangalore, for surface area analysis, Dr Joyce D'Souza, Indian Institute of Technology Madras for TPD analysis. MS 
thanks HMS Institute of Technology (HMSIT), Tumkur authorities for their part-financial help.

\section{References}

1. Corma A 1995 Chem. Rev. 95559

2. Tanabe K and Holderich W F 1999 Appl. Catal. A. 81(2) 399

3. Mohamed Shamshuddin S Z and Nagaraju N 2005 Indian J. Chem. A44 1165

4. Nagaraju N, Peeran M and Devaprasad 1997 React. Kinet. Catal. Lett. 61155

5. Mohamed Shamshuddin S Z, George Kuriakose and Nagaraju N 2005 Indian J. Chem. Technol. 12

6. Sharath K R, Nagaraju N, Murthy K V V S B S R and Narayanan S 2002 Appl. Catal. 226175

7. Otera J 1993 Chem. Rev. 931449

8. Corma A, Iborra S, Miquel S and Primo J $1998 \mathrm{~J}$. Catal. 173315

9. Ilankumaran P and Verkade J G 1999 J. Org. Chem. 643086

10. Chavan S P, Zubaidha P K, Dantale S W, Keshavaraja A, Ramaswamy A V and Ravindranathan T 1996 Tetrahedron Lett. 37233

11. Vane J R and Botting R M (eds) 1992 Aspirin and other salicylates (London: Chapman and Hall) 1st edn
12. Kuriakose G and Nagaraju N $2004 \mathrm{~J}$. Mol. Catal. A223 155

13. Sen S E, Smith S M and Sulivan K A 1998 Tetrahedron 5512657

14. Mercera P D L, Van Ommen J G, Doesburg E B M, Burggraaf A J and Ross J R H 1990 Appl. Catal. 57 127

15. Yadav G D and Nair J J 1999 Micropor. Mesopor. Mater. 331

16. Arata K 1990 Adv. Catal. 37165

17. Hino M and Arata K 1989 Chem. Lett. 971

18. Arata K and Hino M 1989 Shokubai 31477

19. Mohamed Shamshuddin S Z and Nagaraju N 2004 Indian J. Chem. A43 2060

20. Hino M and Arata K 1988 J. Chem. Soc. Chem. Commun. 1259

21. Benesi H A 1957 J. Phys. Chem. 61970

22. Reddy B M and Reddy V R 1999 Synth. Commun. 29(16) 2789

23. Chary K V R, Reddy K R, Kishan G, Niemantsverdriet J W and Mestl G 2004 J. Catal. 226283

24. Kumbhar P S, Yadav V M and Yadav G D 1989 In Chemically modified oxide surfaces (eds) D E Leyden and W T Collins (New York: Gordon and Breach) p. 81

25. Reddy B M, Chowdhury B and Smirniotis P G 2001 Appl. Catal. A211 19 